\title{
School Social Behavior Scales: an Adaptation Study of the Portuguese Version of the Social Competence Scale from SSBS-2
}

\author{
Raquel Raimundo ${ }^{1}$, Elsa Carapito ${ }^{1}$, Ana Isabel Pereira ${ }^{1}$, Alexandra Marques Pinto ${ }^{1}$, \\ Maria Luísa Lima², and Maria Teresa Ribeiro ${ }^{1}$ \\ ${ }^{1}$ Universidade de Lisboa (Portugal) \\ ${ }^{2}$ ISCTE, Instituto Universitário de Lisboa (Portugal)
}

\begin{abstract}
This study analyses the psychometric proprieties of a Portuguese version of the social competence scale from the School Social Behavior Scales (SSBS-2, Merrell, 2002). It is a rating instrument of children and adolescents behavior, to be used by teachers and other school personnel. This scale includes 3 subscales: self-management/compliance, peer relations and academic behavior. In our first sample, 175 teachers rated 344 students from grade 1 through 12 . On the second sample 13 teachers rated $2513 \mathrm{rd}$ and 4 th grades students. The results from the Portuguese adaptation support the multidimensional structure of the social competence scale from the SSBS-2, although an alternative model demonstrated a better fit to the data than the model originally proposed by the author. The scale showed good internal consistency and good intercorrelations between subscales, as well as between subscales and the total scale. The final model was well replicated in the second sample. These results encourage us to pursue the SSBS-2 Portuguese adaptation, in order to provide a useful and validated instrument for the assessment of social competence and for educational interventions.

Keywords: social competence, assessment, validation, School Social Behavior Scales.
\end{abstract}

El presente estudio analiza las características psicométricas de la versión portuguesa de la escala School Social Behavior Scales (SSBS-2, Merrell, 2002). Se trata de un instrumento de calificación del comportamiento de los niños y adolescentes, para ser utilizado por los maestros y por otro personal educativo. Esta escala incluye tres subescalas: autocontrol/conformidad, las relaciones entre pares y el comportamiento académico. En nuestra primera muestra, 175 maestros calificaron 344 estudiantes del $1^{\circ}$ al $12^{\circ}$ grado escolar. En la segunda muestra, 13 profesores calificaron 251 estudiantes de $3^{\circ}$ y $4^{\circ}$ grado escolar. Los resultados de la adaptación portuguesa apoyan la estructura multidimensional de la escala de competencia social del SSBS-2, a pesar de un modelo alternativo demostrar un mejor ajuste a los datos que el modelo propuesto originalmente por el autor. La escala reveló una buena consistencia interna y una buena correlación entre las subescalas, así como entre las subescalas y la escala total. El modelo final se replicó bien en la segunda muestra. Estos resultados nos incentivan a proseguir la adaptación portuguesa del SSBS-2, a fin de proporcionar un instrumento útil y validado para la evaluación de la competencia social y para las intervenciones educativas.

Palabras clave: competencia social, evaluación, validación, School Social Behavior Scales.

This research was funded by two Grants (SFRH/BD/27905/2006 and SFRH/BD/41236/2007) from the Science and Technology Foundation, Portugal. The authors gratefully acknowledge the encouraging support of Kenneth Merrell and also of the teachers who participated in this study. This paper is dedicated to the memory of Kenneth Merrell and his inspiring work and life.

Correspondence concerning this article should be addressed to Raquel Raimundo. Faculdade da Psicologia, Universidade de Lisboa. Alameda da Universidade 1949-013, Lisboa (Portugal). E-mail: rraimundo@campus.ul.pt 
Social competence plays a key role in the adaptive school functioning of children and adolescents, influencing relations with teachers, peer acceptance, and academic achievement (Lemos \& Meneses, 2002). Social competence and social skills also have a great impact on human development, particularly in the success and adjustment in adulthood (Merrell, 1993b, 2002).

Despite the increasing focus of research and intervention on the pro-social behavior, current models of social behavior still concentrate too much on the pathological and non-normative development of youth, making it difficult to assess social behavior in a manner that is reliable, efficient and generalizable (Crowley \& Merrell, 2003; Cummings, Kaminski, \& Merrell, 2008). However, the existence of social skills assessment instruments that are practical, low cost, easy to implement, and have good psychometric properties is a prerequisite to the development of effective interventions targeting social behavior (Merrell, 2001, 2002).

\section{Social Competence}

Social competence is a complex, multidimensional, interactive construct (Merrell, 2002) that encompasses social, attitudinal, cognitive and emotional factors (Consortium on the School-Based Promotion of Social Competence, 1996; Lemos \& Meneses, 2002). Different definitions of this construct can be found in literature, depending on the theoretical perspectives adopted about social functioning and development (Lemos \& Meneses, 2002). Defining social competence became even more complicated when some authors started to include in the definition both the skills and the outcomes of individual actions appropriate to a specific situation (Consortium on School-Based Promotion of Social Competence, 1996).

The majority of social skills definitions emphasize social validity (Caldarella \& Merrell, 1997), influencing the construction of assessment tools that measure these skills, such as the ones developed by Gresham and Elliott (1990) and Merrell (2002). This definition privileges the subject's behavior in specific situations that predict and/or are related to positive social outcomes, such as peer acceptance, popularity and the judgment of behavior by significant others (Gresham \& Elliott, 1984).

Socially competent individuals are those who have the skills necessary to solve problems in such a way that allows them to choose and activate appropriate social behaviors (Bierman \& Welsh, 1997; as cited in Cummings et al., 2008), which can be learned (Lemos \& Meneses, 2002). Caldarella and Merrell (1997) developed a taxonomy of social skills of children and adolescents based on published empirical studies, manuals and assessment tools. Eighteen of the 19 studies analyzed mention at least one of the five dimensions put forth by the authors as core social skills: (1) peer relations, (2) self-management, (3) academic, (4) compliance and (5) assertion. Although all social skills are, to some degree, interdependent, they can be grouped into distinct categories (Caldarella \& Merrell, 1997).

Social competence: antecedents and impact on adjustment. Children's early life experiences contribute to the development of a competent social functioning towards adults and peers in their socio-cultural context (Feldman \& Masalha, 2010). Parental modeling of emotional expression, the way parents manage children's emotions (Denham, Mitchell-Copeland, Stranberg, Auerbach, \& Blair, 1997), family cohesion (Feldman \& Masalha, 2010), parental psychopathology, family stress and other childhood adversities (DeMulder, Denham, Schmidt, \& Mitchell, 2000) are important predictors of social competence (Denham et al., 1997; Feldman \& Masalha, 2010).

The children of emotionally positive parents (Denham et al., 1997), children with a secure attachment to the mother and children with low family stress (DeMulder et al., 2000) show greater social competence and fewer behavioral problems (DeMulder et al., 2000; Schmidt, DeMulder, \& Denham, 2002). In contrast, poverty, low socio-economic status, residing in high-crime neighborhoods and parental conflict or divorce are significant ecological predictors of behavioral problems in children and adolescents, indirectly influencing the relationship between parents and children and affecting children's exposure to peer groups with deviant behavior (Granic \& Patterson, 2006).

But it is also possible to promote social competence in children and adolescents via universal or selective intervention programs implemented inside or outside the school. The effectiveness of these programs is supported by several studies (Catalano, Berglung, Ryan, Lonczak, \& Hawkins, 2002; Durlak, Weissberg, Dymnicki, Taylor, \& Schellinger, 2011; Durlak, Weissberg, \& Pachan, 2010; Greenberg, Domitrovich, \& Bumbarger, 2001).

Developing adjusted social competences leads to positive and effective interactions with others (Consortium on the School-Based Promotion of Social Competence, 1996; Gresham \& Elliott, 1990; Lemos \& Meneses, 2002), academic success (Gresham \& Elliott, 1990) and buffers against relationships that promote socially unacceptable behaviors (Lemos \& Meneses, 2002). Furthermore, social deficits in childhood can lead, in the short and long-term, to academic difficulties and poor school adjustment, school dropout, rejection by peers (Cummings et al., 2008; Merrell, 1993b, 2002), depression and anxiety, juvenile delinquency, mental health problems, development of antisocial behavior patterns (Cummings et al., 2008; Merrell, 1993b, 2002; Walker, Colvin, \& Ramsey, 1995, as cited in Caldarella \& Merrell, 1997), unemployment, underemployment, inadequate social support and unsatisfactory interpersonal and family relationships (Merrell, 1993b, 2002). All these negative consequences carry a high cost to the individuals, their families and the society (Merrell, 2002). 
Social Skills Evaluation

Merrell (2001) identifies six primary methods of assessing the social skills of children and adolescents: behavior rating scales, behavioral observation, interviewing, self-report instruments, projective-expressive techniques, and sociometric techniques.

The behavior rating scales provide a standardized format for making judgments about the characteristics of social behavior in children and adolescents. These scales are focused on estimates based on daily observations of youth while they are in their natural environment (e.g., school, home) over a period of time, by people who know the youth well (e.g., parents and teachers). These scales have advantages over other methods of evaluation. Compared to interviews and observations, behavior rating scales are less expensive, less time consuming and require less training for application. Unlike behavioral observation, they permit the evaluation of low frequency but very relevant behaviors. Finally, they have advantages over self-report scales because they can be used to assess children who cannot readily provide information about themselves. In short, behavior rating scales are a valuable and cost-effective method of screening and assessing the socio-emotional behavior of children and youth (Crowley \& Merrell, 2003; Merrell, 2001).

However, rating scales only measure behavioral competence in a specific point in time and are less sensitive to changes in behavior or learning (Cummings et al., 2008), rending them difficult to use for characterizing young people's trajectories of growth and development.

Rating scales based on teachers' reports are one of the most widely used methods of assessing social behavior in young people (Caldarella \& Merrell, 1997; Merrell, 1993b), especially social skills (Cummings et al., 2008). Their main strength resides in their being based on large samples of observed behavior, during extended periods of time (Lemos \& Meneses, 2002).

\section{The School Social Behavior Scales - SSBS-2}

The SSBS-2 is an improved version of the original instrument published in 1993 (SSBS; Merrell, 1993a) developed specifically for screening and assessing social competence and antisocial behavior of students from 1st to 12 th grade. It was designed to facilitate the development of appropriate prevention and intervention programs and for evaluating the effectiveness of interventions. The SSBS2 includes two behavior rating scales for teachers and other school-based raters: the Social Competence Scale and the Antisocial Behavior Scale. The SSBS-2 Social Competence Scale describes adaptive or positive behaviors that are likely to lead to positive personal and social outcomes for students. The SSBS-2 Antisocial Behavior Scale describes common social-related behavioral problems of children and youth (Merrell, 2002).
Several studies concerning the instrument's psychometric properties, reported in SSBS-2 manual and subsequent publications, have demonstrated a satisfactory internal consistency, test-retest reliability at 3-week intervals and interrater reliability. Validity of the scales has been demonstrated in several ways, including convergent and discriminant validity with other behavior rating scales, evidence of strong sensitivity to theoretically-based group differences (e.g., special education, gifted students, at-risk children) and intervention programs evaluation, as well as convergence with other types of assessment such as sociometric procedures, self-report instruments and behavioral observations (Cummings et al., 2008; Merrell, 2001, 2002).

Crowley and Merrell (2003) analyzed the original scale factor structure through confirmatory factor analysis. Item packets, testlets or mini-scales of three or four items were used for each subscale, in a total of ten. The final model fit indices showed acceptable values, thus supporting the scale use for the assessment of social competence.

The SSBS-2 instrument was translated into several languages and has been object of research in several countries (K. Merrell, personal communication, 26th September, 2010). In the literature there is only reference to a Turkish version of SSBS with children from the 1st and 2nd grades (Yukay-Yuksel, 2009). The author concluded that the Turkish version of the SSBS was appropriate for evaluating the student's level of social competence in the 1 st and 2 nd grades (elementary school), since it had acceptable validity and reliability. Confirmatory factor analysis of the original structure of the instrument revealed weaknesses, however, the author still chose to keep it.

There are other technically appropriate rating scales with good psychometric qualities that have proven useful to assess children's and adolescents' social behavior (Merrell, 2002), such as the Walker-McConnell Scale of Social Competence and School Adjustment - SSCSA (1988, as cited in Merrell, 1993b), the Social Skills Rating System - SSRS by Gresham and Elliott (1990), and the Social Skills Improvement System - Rating Scales - SSIS, by Gresham and Elliott (2008), which is a more recent and improved version of SSRS. However the SSBS have unique advantages for assessing the wider social behavior because they include items related to social competence and antisocial behavior assessment in a similar proportion (Merrell, 1993b). As for the SSCSA, it does not include an assessment of behavioral problems and the SSIS and SSRS were built with a special focus on positive social behaviors although they allow for a brief assessment of behavioral problems (Merrell, 1993b).

In Portugal, the assessment of social competence has received increasing attention in the last decade, but the publication of studies related to the development and/or adaptation of Portuguese assessment tools continues to fall short. Social competence rating scale adaptation studies using confirmatory factor analysis methodology are unheard of in our country, despite it being considered the most 
appropriate methodology when a specific structure was already found for a given assessment tool and the researchers wish to analyze that structure with different samples (Crowley \& Merrell, 2003). So far we only have two published adaptations, both of the Social Skills Rating System - SSRS (Gresham \& Elliott, 1990), with acceptable results in the validation studies (reliability and validity): the teachers version (hetero-report) for elementary and middle school (1st to 6th grade) by Lemos and Meneses (2002), with participants from the 3rd and 6th grades; and the students version (self-report) for middle and high school students (7th to 12th grade) by Pedro and Albuquerque (2007), with students from the 7th, 8th and 9th grades. It is also worth mentioning the adaptation and validation studies of a social skills and behavior problems assessment tool for Portuguese preschoolers, the Preschool and Kindergarten Behavior Scales - 2 (PKBS-2, Merrell, 2002), which are still ongoing but have confirmed the good psychometric properties of the PKBS-2 (teachers' and parents' versions) in a sample of children from three to sixyear-olds (Major, 2007; Major \& Seabra-Santos, 2009).

Gomes (2008) conducted a research to examine whether the Social Competence Scale of the Portuguese version of the SSBS-2 would be an effective tool to differentiate children considered at risk from children who are not considered at risk in a matched sample in terms of gender and age. The results showed that the children from the first group had significantly lower levels of social competence than children from the second group. In both groups, girls had higher levels of social competence than boys. The results also showed the instrument effectiveness in classifying children within each group, based on the teachers' responses.

\section{The present study}

Taking into account the limited amount of research of this nature in Portugal, and the need to make available for research and intervention an assessment tool adapted to the Portuguese school population from the 1 st to the 12th grades, this study aims to present the first steps of the School Social Behavior Scales - 2 (SSBS-2; Merrell, 2002) adaptation and validation. The present research focuses only on the Social Competence scale evaluation, since the Antisocial Behavior Scale of SSBS-2 research evaluation will be mentioned in a future publication.
Method

\section{Participants}

Two samples (sample one and sample two) were gathered for this study. The first sample was used to study the sensitivity, validity and reliability of the Social Competence scale while the second sample was used for cross-validation of the same scale. Participants in both samples differ in many respects. The sample 1 consists of 175 teachers, mostly female $(81.1 \%)$, from public $(74.3 \%)$, private $(12.6 \%)$ and nonprofit private schools (13.1\%) of seven districts of mainland Portugal. Teachers completed a total of 344 scales, one per student, 187 male and 157 female, aged six to $18(M=12.13, S D=3.37)$. Students attended 1 st to 12 th grades ${ }^{1}$. Sample 2 was comprised of 13 teachers, mostly female $(92.3 \%)$, from six public schools from the Lisbon district. These teachers completed a total of 251 scales, one per student, 133 male students and 118 female students, aged eight to $14(M=9.32, S D=.78)$. Students attended the 3 rd $(3.2 \%)$ or the 4 th $(96.8 \%)$ grades.

\section{Measure}

Items of the SSBS-2 Social Competence Scale were first translated from English to Portuguese by two researchers with a psychology degree and proficient in English, after obtaining authorization, for the Portuguese adaptation, from the author of the scale. A professional translator made the retroversion of both Portuguese translations into English and the items more faithfully translated from the original version were selected. The 32 items that make up the scale assess the frequency of students' positive social behaviors likely to occur in the school context, from the 1st to the 12th grades. Behaviors are assessed using a Likert response scale from 1 (never) to 5 (very often).

The Social Competence Scale is organized into three empirically derived subscales: Peer Relations (14 items), SelfManagement (10 items) and Academic Behavior (eight items). The Peer Relations subscale refers to items that measure social skills or characteristics that are important in establishing positive relationships with and gaining social acceptance from peers (e.g., "Offers help to other students when needed", "Invites other students to participate in activities"). The Self-Management subscale includes items which measure social skills related to

\footnotetext{
1 Despite the apparent age differences in the development of social competence (Conger \& Keane, 1981; Eisenberg \& Harris, 1984) and the difficulty in finding assessment tools with good psychometric qualities that evaluate the same theoretical constructs throughout different developmental stages (Denham, Wyatt, Bassett, Echeverria, \& Knox, 2009), the option for a sample with such a vast range of ages was due to the fact that literature seems to point to the inexistence of significant age differences regarding social competence. In the analysis made by Caldarella and Merrell (1997), none of the 19 published studies about social abilities found significant differences between older and younger children and the majority of these studies identified similar factors or dimensions throughout age. Moreover, in Merrell's (2002) study with the original sample of the SSBS-2, the effect size of the differences on social competence between the 1 st to the 6 th grades group and the 7 th to the 12 th grades group, was close to $0(.02)$.
} 
self-restraint, cooperation, and compliance with the demands of school rules and expectations (e.g., "Remains calm when problems arise", "Responds appropriately when corrected by teachers"). The Academic Behavior subscale consists of items related to competent performance and engagement on academic tasks (e.g., "Completes school work without being reminded", "Produces work of acceptable quality for his/her ability level").

In its original version this scale demonstrated good psychometric properties, showing a strong internal consistency (.91 to .98), good accuracy in a test-retest interval of three weeks (.76 to .83$)$ and good inter-rater agreement (.72 to .83). In confirmatory factor analysis of the original scale indices of adjustment of the final model revealed acceptable values $\left(\chi^{2}(29)=389.55, p<.001, \chi^{2} / d f=14.433\right.$; CFI $=.97$; GFI $=.93$; RMSEA $=.11)$ (Crowley \& Merrell, 2003).

\section{Procedure}

Samples were obtained from different methodological choices, since they were selected for two separate studies using the Social Competence Scale of SSBS-2, with different purposes. Thus, for the collection of data from sample $1(n=344)$ each teacher received two copies of the scale to complete, regarding two students: the 5th and the 10 th from the list of students in their class, which was ordered alphabetically. This was done to prevent biased choices (either for positive or negative reasons) regarding the students the teachers were going to evaluate. Each teacher was asked to complete the scales and to give them back to the investigator in a sealed envelope. Sample 2 ( $n$ = 251) was obtained by having teachers evaluate all the students in their class. This sample was also used to assess the impact of a socio-emotional learning program implemented in the 4 th grade. In this study, sample 2 was only used as a cross-validation sample of the final model.

\section{Statistical Analysis}

The database of the present study was built using the SPSS program (version 17.0) that had also been used to analyze the sensitivity and reliability of the Social Competence Scale of the SSBS-2. The study of the factorial validity of the scale, as well as the cross-validation to test the invariance of the model, was conducted using the AMOS software (version 7.0). The sensitivity of the items was assessed by the coefficients of skewness and kurtosis. It was considered that skewness coefficient values above three and kurtosis coefficient values below seven represented significant deviation from normality (Kline, 1998).
In the confirmatory factor analysis (CFA), the same procedure Crowley and Merrell (2003) used for the original scale was followed. A combination of items (testlets), between two and four, was used, creating mini-scales (three to four sets of items per subscale). The use of mini-scales, suggested by Collins and Gleaves (1998), was adopted as a way to overcome the reduced reliability associated with the items when considered individually in a CFA (Floyd \& Widaman, 1995).

Next, the factorial validity of the tri-factorial measurement model was tested. First, it was adopted a strictly confirmatory approach to test the adequacy of the data to the model. Second, there was an attempt to improve the model and, finally, a factorial invariance analysis was conducted using a multigroup confirmatory factor analysis. The following indices of goodness-of-fit were used: the chi-square $\left(X^{2}\right)$, the chi-square and degrees of freedom ratio $\left(\chi^{2} / d f\right)$, the comparative fit index $(C F I)$, the goodness-of-fit index $(G F I)$ and the root mean square error of approximation (RMSEA).

The quality of alternative models was also assessed in comparative terms, using the $\Delta \chi^{2}$ and the $\Delta \mathrm{CFI}^{2}$. For the purpose of comparing alternative models it was considered that the model with lower value of $\chi^{2}$ is what has better quality of adjustment. The refinement of the model was based on modification indices calculated by AMOS, pursued only if they were adequate from the statistical and substantive points of view (Byrne, 2010). Trajectories were changed and/or items were eliminated in the presence of modification indices above $11\left[\chi^{2}(1)=10.86, p=.001\right]$ (Maroco, 2010).

The reliability was assessed with Cronbach's alpha for each of the three factors and for the total scale. The Pearson correlation coefficient between mini-scales and subscales and between subscales and total scale was also used to analyze the internal consistency. The robustness of the final model was further analyzed with the AMOS program by using a cross-validation with a multigroup confirmatory factor analysis, which included two independent samples (sample 1 and sample 2). This analysis permitted a test of the factorial invariance (measurement and structural model), i.e., the extent to which the mini-scales of the Scale of Social Competence of the SSBS-2 operate in a similar manner in both samples and whether the factorial structure remains the same (Byrne, 2010). To test the invariance of the model it was used the $\Delta \chi^{2}$ and the $\triangle C F I$, i.e., the difference in $\chi^{2}$ and in CFI between the configural model and the measurement and structural models, respectively.

Finally, an analysis of variance (oneway ANOVA) of the means and standard deviations was made for the total scale and subscales in terms of socio-demographic variables.

\footnotetext{
2 It was considered that CFI and GFI values above 0.95, RMSEA values below .06 (Hu \& Bentler, 1999) and $\chi^{2} / d f$ values equal to or below 3 (Segars \& Grover, 1993) were good model fits. RMSEA values between .06 and .08 were considered acceptable, between .08 and .10 tolerable, and unacceptable when they were above .10 (Browne \& Cudeck, 1992).
} 
Results

\section{Sensitivity, Validity and Reliability of the Social Competence Scale of SSBS-2}

Table 1 presents the descriptive statistics, for sample 1, of the 10 mini-scales that constitute the Social Competence Scale of the SSBS-2: the average $(M)$, the standard deviation $(S D)$, the skeweness $(S k)$ and the kurtosis $(K u)$. All of them have symmetry and pointyness values very close to the normal distribution. The values obtained in all these indicators are adequate and do not recommend the removal of any of the mini-scales from the scale.

Factorial validity was tested through a confirmatory factor analysis of the final model proposed by Crowley and Merrell (2003).

Some of the goodness-of-fit indices show that the factorial validity of the original structure of the scale in sample 1 ranges from tolerable $\left(\chi^{2} / d f\right)$ to unacceptable (RMSEA) $\left[\chi^{2}(29)=139.753, p<.001, \chi^{2} / d f=4.819\right.$; CFI $=.969 ; \mathrm{GFI}=.923$; RMSEA $=.106]($ see Figure 1$)$, although some indices (CFI and GFI) present acceptable values of adjustment and the factorial loadings of all miniscales except one are higher than .59. Based on these goodness-of-fit scores, some changes in the model were introduced following the modification indices provided by AMOS. For this reason, mini-scale Peers 3 was eliminated from the Peer Relations dimension, as the modification indices suggested a correlation of its measurement error with several measurement errors from other mini-scales in the same or in other dimensions. The goodness-of-fit values for this first modified model $\left[\chi^{2}(21)=51.706, p<.001\right.$, $\left.\chi^{2} / d f=2.462 ; \mathrm{CFI}=.990 ; \mathrm{GFI}=.969 ; \mathrm{RMSEA}=.065\right]$ show a substantial improvement $\left[\Delta \chi^{2}(8)=88.047, p<\right.$ $.01]$, although the factorial loadings of Peers1 mini-scale, which load both on Peer Relations (.59) and on Self-
Management (.30) subscales, are bellow the other factorial loadings. All the remaining values are equal or higher than .75. Self1 is a mini-scale that is associated with selfmanagement in social interactions, and for this reason it is also expected to load on the subscale Peer Relations. This led to its elimination and, as a result, the correlation between measurement errors of Peers1 and Self1 disappeared.

In line with the options made by the author of the original scale (Crowley \& Merrell, 2003), and considering that the measurement errors are often the result of the perceived redundancy in the content of the items (Byrne, 2010), the correlation between the measurement errors of mini-scales Acad1 and Acad3 was allowed. This association is justified as both mini-scales include items related to classroom tasks. The goodness-of-fit values of this new model are good $\left[\chi^{2}(16)=31.034, p=.013, \chi^{2} / d f=1.940\right.$; $\mathrm{CFI}=.994 ; \mathrm{GFI}=.978 ; \mathrm{RMSEA}=.052]$ and significantly better than those of the first modified model $\left[\Delta \chi^{2}(5)=\right.$ $20.672, p<.01]$, attesting the high factorial validity of the final modified Social Competence Scale of the SSBS-2 (see Figure 2).

In the final modified model, for sample 1, the Cronbach alpha values for the factors Peer Relations (three mini-scales), Self-Management (two mini-scales) and Academic Behavior (three mini-scales) were $.91, .83$ and .91 , respectively. The Cronbach alpha for the total scale is .94. The correlations between each mini-scale and the respective subscales range between .90 and .96; the correlations of each mini-scale and the total score of the scale are between .71 and .90 .

\section{Cross-Validation of the Social Competence Scale of the SSBS-2}

A second independent sample was collected (sample 2) and used in this study as a cross-validation sample for the final modified model. The goodness-of-fit values of this

Table 1

Sensibility of Item Packets of the Social Competence Scale of the SSBS -2

\begin{tabular}{|c|c|c|c|c|c|c|}
\hline Item Packets & $M$ & $S D$ & Skewness & Kurtosis & Minimum & Maximum \\
\hline Peers1 & 10.19 & 2.50 & -.222 & -.350 & 3 & 15 \\
\hline Peers2 & 10.16 & 2.47 & -.314 & -.258 & 3 & 15 \\
\hline Peers3 & 13.54 & 3.42 & -.164 & -.572 & 5 & 20 \\
\hline Peers4 & 13.82 & 2.99 & -.176 & -.413 & 5 & 20 \\
\hline Self1 & 10.94 & 2.25 & -.382 & -.093 & 4 & 15 \\
\hline Self2 & 10.65 & 2.70 & -.365 & -.282 & 3 & 15 \\
\hline Self3 & 11.32 & 2.43 & -.506 & -.327 & 3 & 15 \\
\hline Acad1 & 10.55 & 3.04 & -.206 & -.806 & 3 & 15 \\
\hline Acad2 & 11.32 & 2.55 & -.317 & -.518 & 3 & 15 \\
\hline Acad3 & 7.02 & 1.89 & -.192 & -.653 & 2 & 10 \\
\hline
\end{tabular}

Note. Peers1 = Peer Relations 1; Peers2 = Peer Relations 2; Peers3 = Peer Relations 3; Peers4 = Peer Relations 4; Self1 = Self-Control 1; Self2 = Self-Control 2; Self3 = Self-Control 3; Acad1 = Academic Behavior 1; Acad2 = Academic Behavior 2; Acad3 = Academic Behavior 3. 


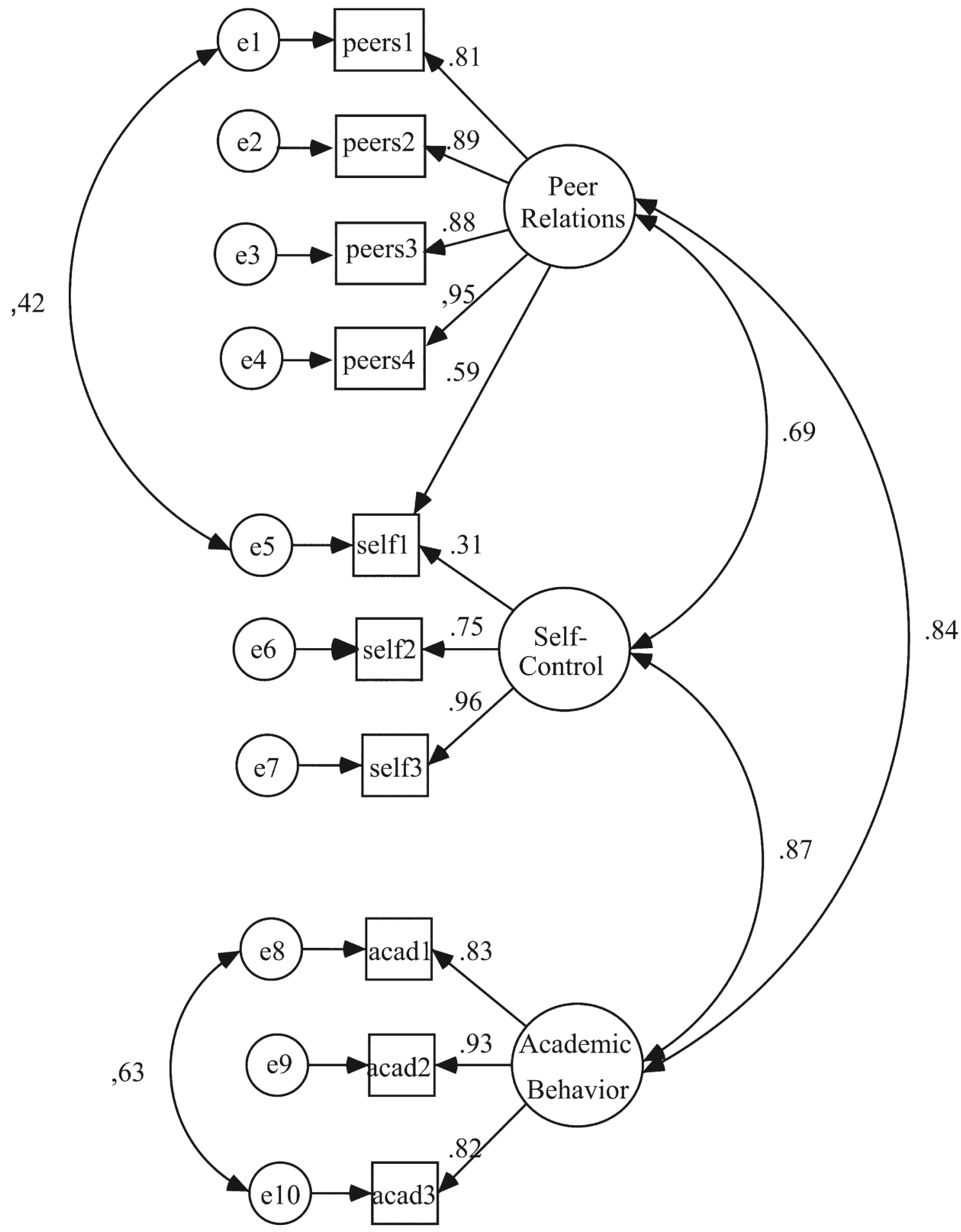

Figure 1. Final model for Social Competence Scale proposed by Crowley and Merrell (2003). 


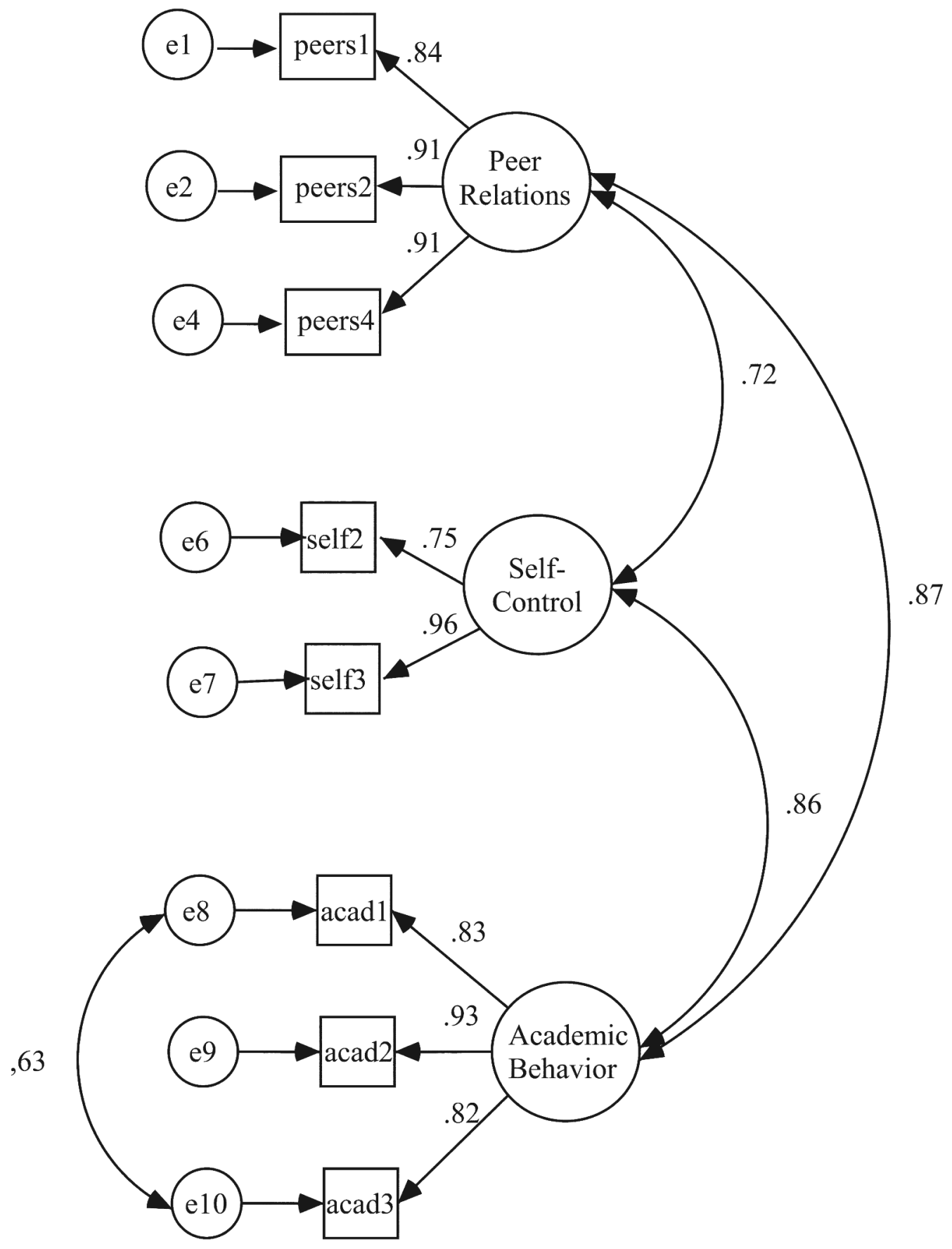

Figure 2. Modified final model for Social Competence Scale of the SSBS-2. 
last model regarding sample 2 are less adequate $\left[\chi^{2}(16)=\right.$ 56.211, $p<.001, \chi^{2} / d f=3.513$; CFI = .983; GFI = .949; RMSEA $=.100]$, but they are still quite acceptable. In this sample the reliability of the factors Peer Relations (three mini-scales), Self- Management (two mini-scales) and Academic Behavior (three mini-scales), given by the Cronbach alpha, is .94, .87 and .91, respectively, and .96 for the total scale.

The data on table 2 reveal the invariance of the model regarding the factor loadings of the mini-scales on the factors $\left(\Delta \chi^{2}(5)=9.060, p=.107 ; \Delta \mathrm{CFI}<.001\right)$, i.e., measurement invariance. However, the results relative to the structural invariance revealed by $\Delta \chi^{2}$ and $\Delta$ CFI are contradictory. The invariance is confirmed if $\Delta \mathrm{CFI}$ is considered $(\Delta \mathrm{CFI}=.004<.01)$, but not if $\Delta \chi^{2}$ is taken into account $\left(\Delta \chi^{2}(11)=30.832, p<.01\right)$. Cheung and Rensvold (2002) recommend the use of $\Delta$ CFI $(<.01)$ instead of $\Delta \chi^{2}(>.05)$, because the first measure is independent of the complexity of the model and of sample size.
This cross-validation with two samples to test the invariance of the proposed model has shown both structural and measurement invariance for the Social Competence Scale of the SSBS-2. The final modified model presents a good fit to the data and an adequate approximation to both samples.

Table 3 presents the means and standards deviations obtained for the total scale and the subscales in sample 1, considering the socio-demographic variables. Oneway ANOVA tests revealed significant gender differences, with girls presenting significantly higher levels of social competence $\left(F(1,342)=5.569, p=.02, \eta_{\mathrm{p}}{ }^{2}=.02\right)$ and self-management $\left(F(1,342)=15.752, p<.01, \eta_{\mathrm{p}}{ }^{2}=.04\right)$ than boys, although the effect size is small. Age groups did not produce any significant difference in these means and there was only one marginally significant educational level effect: students from elementary school tend to present more positive levels of peer relations when compared with students from other educational levels $(F(3,340)=2.521$, $\left.p<.06, \eta_{\mathrm{p}}^{2}=.02\right)$.

Table 2

Goodness-of-Fit of Multigroup Confirmatory Factor Analysis

\begin{tabular}{lcccccccc}
\hline Model & $\chi^{2}$ & $d f$ & $p$ & $\Delta \chi^{2}$ & $\Delta d f$ & $p$ & CFI & $\Delta$ CFI \\
\hline Configural & 87.245 & 32 & .000 & - & - & - & .989 & - \\
Measurement & 96.306 & 37 & .000 & 9.060 & 5 & NS & .989 & .000 \\
Structural & 118.077 & 43 & .000 & 30.832 & 11 & .001 & .985 & .004 \\
\hline
\end{tabular}

Table 3

Mean Values (M) and Standard Deviation (SD) of the Social Competence Scale and Subscales regarding Gender, Age and Educational Level

\begin{tabular}{|c|c|c|c|c|}
\hline Socio-demographic Variables & $\begin{array}{c}\text { Social Competence } \\
\qquad M(S D)\end{array}$ & $\begin{array}{c}\text { Peer Relations } \\
\quad M(S D)\end{array}$ & $\begin{array}{c}\text { Self - Control } \\
M(S D)\end{array}$ & $\begin{array}{c}\text { Academic Behavior } \\
M(S D)\end{array}$ \\
\hline \multicolumn{5}{|l|}{ Gender } \\
\hline Female $(n=157)$ & $10.93(1.93)$ & $11.57(2.32)$ & $11.53(2.03)$ & $9.88(2.14)$ \\
\hline Male $(n=187)$ & $10.38(2.31)$ & $11.24(2.56)$ & $10.53(2.55)$ & $9.42(2.47)$ \\
\hline \multicolumn{5}{|l|}{ Age } \\
\hline $6-9(n=87)$ & $11.10(2.11)$ & $11.96(2.41)$ & $11.30(2.27)$ & $10.10(2.40)$ \\
\hline $10-12(n=110)$ & $10.50(2.17)$ & $11.18(2.36)$ & $10.76(2.49)$ & $9.64(2.33)$ \\
\hline $13-15(n=75)$ & $10.40(2.31)$ & $11.10(2.76)$ & $10.89(2.47)$ & $9.36(2.44)$ \\
\hline $16-18(n=72)$ & $10.51(2.00)$ & $11.34(2.27)$ & $11.06(2.23)$ & $9.32(2.09)$ \\
\hline \multicolumn{5}{|l|}{ Educational Level } \\
\hline Elementary $(n=104)$ & $11.04(2.13)$ & $11.89(2.38)$ & $11.17(2.38)$ & $10.11(2.39)$ \\
\hline Early Middle $(n=82)$ & $10.32(2.26)$ & $11.03(2.62)$ & $10.73(2.50)$ & $9.33(2.37)$ \\
\hline Late Middle $(n=91)$ & $10.42(2.11)$ & $11.10(2.44)$ & $10.87(2.29)$ & $9.44(2.29)$ \\
\hline $\operatorname{High}(n=67)$ & $10.66(2.09)$ & $11.47(2.31)$ & $11.18(2.35)$ & $9.51(2.19)$ \\
\hline
\end{tabular}

Note . Elementary = Elementary School; Early Middle = Early Middle School; Late Middle = Late Middle School; High = High School. 


\section{Discussion}

This study proposed to analyze the psychometric characteristics of the Portuguese version of the Social Competence Scale of the SSBS-2. Two samples with 188 teachers from public schools, private for-profit schools and private nonprofit schools, from seven different districts of Portugal, evaluated a total of 595 students, aged six to 18 , from 1 st to 12 th grades. The study aimed to offer an adaptation of a valid assessment measure of social competence, whether for research or intervention purposes in this area, both in clinical and educational contexts.

The study of the sensitivity of the mini-scales of the SSBS-2 Scale of Social Competence shows an adequate distribution of results, differentiating the participants based on their social competence. As for the factorial validity, the results of this study support the multidimensional structure of social competence held by the author of the original scale (Crowley \& Merrell, 2003; Merrell, 2002), although the final structure has not been exactly replicated. The factorial structure found in the Portuguese sample presents more appropriate goodness-of-fit values than the original structure of the scale proposed by the authors, although it was necessary to remove items from the scale.

Regarding reliability, the results show internal consistency indices for the mini-scales and the total scale ranging from good to very good, similar to results reported by Gomes (2008) in another Portuguese study using the Social Competence Scale of the SSBS-2. The relationships found between the subscales of the Social Competence Scale are very similar to those found by the author of the original scale (Crowley \& Merrell, 2003), suggesting a strong relationship between the constructs represented by each subscale (Merrell, 2002), particularly between the academic behavior subscale and the remaining subscales. According to DiPerna (2006) the academic competence encompasses not only academic skills, i.e., the basic and complex cognitive abilities (e.g., math, reading, critical thinking) that constitute the main target of academic instruction, but also the academic facilitators, i.e., the attitudes and behaviors that facilitate students' participation in academic instruction (e.g., interpersonal skills, study skills, motivation and commitment). In this sense, it is not surprising to find that some skills necessary for a positive interaction between peers during childhood and adolescence are also essential to succeed in school (Caldarella \& Merrell, 1997). Peer relations can serve as facilitators in that they promote new learning contexts and motivate students to commit themselves to learning activities and to socially appropriate behaviors (Wentzel \& Watkins, 2002).

Regarding the model's test of invariance, the fact that the structural invariance has been confirmed by only one indicator $(\triangle \mathrm{CFI})$ is justifiable because a different methodology for collecting data for sample 2 was adopted.

Gender differences found in the first sample - girls showing higher mean values on social competence than boys - support the data obtained by the author of the scale (Merrell, 2002), as well as those referred by Gomes (2008). The absence of significant differences according to educational level corroborates the results obtained by Merrell (2002) with the North American sample.

Considering the results as a whole, it may be concluded that the scale presents good psychometric properties, both in terms of its validity and reliability and of its level of invariance of measurement and structure in two different samples, which validates the relevance of the Social Competence Scale of the SSBS-2 as an evaluation tool for children and youth.

The SSBS-2 scales offer some unique advantages. They focus specifically on social functioning (Crowley \& Merrell, 2003; Merrell, 2002) and include social skills and antisocial behavior problems that are typical, general and common, and not psychopathological symptoms or psychiatric disorders. They are easy to apply and to quote and they are brief (Merrell, 2001, 2002), but comprehensive enough to afford a detailed screening of social and antisocial behavior. Furthermore, the SSBS-2 are written in an accessible language for evaluators (teachers) (Merrell, 2002) and, together with the Home and Community Social Behavior Scales (HCSBS-2, Caldarella \& Merrell, 2002) - , completed by parents or by other elements of the community - make up a battery of instruments designed to assess the social and antisocial behavior in a variety of contexts and by different informants (Merrell, 2001, 2002).

\section{Limitations and Future Studies}

Despite these promising results, it should be noted that the samples collected in this study were convenience samples and, as such, are not necessarily representative of the Portuguese population. In addition, each teacher rated several children, not just one, otherwise the sample size would be insufficient for the analysis carried out.

Further research is recommended, particularly regarding the analysis of the scale's validity (e.g., criterion validity, convergent and discriminant validity) and reliability based on other indicators (e.g., test-retest method), to continue to demonstrate the relevance and appropriateness of the use of the SSBS-2 in the Portuguese context. It is also important to pursue the study of scale invariance. This could be done, for instance, by collecting data for a cross-validation sample with a procedure similar to the collection of data from sample 1. Specifically regarding the study of scale invariance, it is important to carry out further investigations to test for variables such as gender, age and ethnicity allowing for a better understanding of its strengths and limitations (Crowley \& Merrell, 2003). It should also be considered the importance of conducting studies with broader samples to examine developmental differences (Caldarella \& Merrell, 1997) and to allow for the development of norm references for age and gender. This is particularly relevant for national 
research given the lack of studies on the assessment of social competence with a broad spectrum of age groups. The Portuguese studies published to date (Gomes, 2008; Lemos \& Meneses, 2002; Pedro \& Albuquerque, 2007) focused only on specific age groups.

\section{References}

Browne, M. W., \& Cudeck, R. (1992). Alternative ways of assessing model fit. Sociological Methods \& Research, 21, 230-258 http://dx.doi.org/10.1177/0049124192021002005

Byrne, B. M. (2010). Structural equation modeling with AMOS: Basic concepts, applications, and programming. New York, NY: Routledge.

Caldarella, P., \& Merrell, K. W. (1997). Common dimensions of social skills of children and adolescents: A taxonomy of positive behaviors. School Psychology Review, 26, 264-278.

Caldarella, P., \& Merrell, K. W. (2002). Home \& Community Social Behavior Scales. Eugene, OR: Assessment-Intervention Resources.

Catalano, R. F., Berglung, M. L., Ryan, J. A. M., Lonczak, H. S., \& Hawkins, J. D. (2002). Positive youth development in the United States: Research findings on evaluations of positive youth development programs. Prevention \& Treatment, 5, Article 15. http://dx.doi.org/10.1037/1522-3736.5.1.515a

Cheung, G. W., \& Rensvold, R. B. (2002). Evaluating goodnessof-fit indexes for testing measurement invariance. Structural Equation Modeling: A Multidisciplinary Journal, 9, 233-255. http://dx.doi.org/10.1207/S15328007SEM0902_5

Collins, J. M., \& Gleaves, D. H. (1998). Race, job applicants, and the five-factor model of personality: Implications for black psychology, industrial/organizational psychology, and the fivefactor theory. Journal of Applied Psychology, 83, 531-544. http://dx.doi.org/10.1037//0021-9010.83.4.531

Conger, J. C., \& Keane, S. P. (1981). Social skills intervention in the treatment of isolated or withdrawn children. Psychological Bulletin, 90, 478-495. http://dx.doi.org/10.1037//00332909.90.3.478

Consortium on the School-Based Promotion of Social Competence (1996). The school-based promotion of social competence: Theory, research, practice, and policy. In R. J. Haggerty, L. R. Sherrod, N. Garmezy, \& M. Rutter (Eds.), Stress, risk, and resilience in children and adolescents: Processes, mechanisms, and interventions (pp. 268-316). New York, NY: Cambridge University Press.

Crowley, S. L., \& Merrell, K. W. (2003). The structure of the School Social Behavior Scales: A confirmatory factor analysis. Assessment for Effective Intervention, 28, 41-55. http://dx.doi.org/10.1177/073724770302800205

Cummings, K. D., Kaminski, R. A., \& Merrell, K. W. (2008). Advances in the assessment of social competence: Findings from a preliminary investigation of a general outcome measure for social behavior. Psychology in the Schools, 45, 930-946. http://dx.doi.org/10.1002/pits.20343
DeMulder, E. K., Denham, S., Schmidt, M., \& Mitchell, J. (2000). Q-sort assessment of attachment security during the preschool years: Links from home to school. Developmental Psychology, 36, 274-282. http://dx.doi.org/10.1037//0012-1649.36.2.274

Denham, S. A., Mitchell-Copeland, J., Strandberg, K., Auerbach, S., \& Blair, K. (1997). Parental contributions to preschoolers' emotional competence: Direct and indirect effects. Motivation and Emotion, 21, 65-86. http://dx.doi.org/10.1023/A:10244 26431247

Denham, S. A., Wyatt, T. M., Bassett, H. H., Echeverria, D., \& Knox, S. S. (2009). Assessing social-emotional development in children from a longitudinal perspective. Journal of Epidemiology \& Community Health, 63, 37-52. http://dx.doi.org/ 10.1136/jech.2007.070797

DiPerna, J. C. (2006). Academic enablers and student achievement: Implications for assessment and intervention services in the schools. Psychology in the Schools, 43, 7-17. http://dx.doi.org/10.1002/pits.20125

Durlak, J., Weissberg, R., Dyminicki, A., Taylor, R., \& Schellinger, K. (2011). The impact of enhancing students' social and emotional learning: A meta-analysis of schoolbased universal interventions. Child Development, 82, 405432. http://dx.doi.org/10.1111/j.1467-8624.2010.01564.x

Durlak, J. A., Weissberg, R. P., \& Pachan, M. (2010). A metaanalysis of after-school programs that seek to promote personal and social skills in children and adolescents. American Journal of Community Psychology, 45, 294-309. http://dx.doi.org/ 10.1007/s10464-010-9300-6

Eisenberg, N., \& Harris, J. D. (1984). Social competence: A developmental perspective. School Psychology Review, 13, 267-277.

Feldman, R., \& Masalha, S. (2010). Parent-child and triadic antecedents of children's social competence: Cultural specificity, shared process. Developmental Psychology, 46, 455-467. http://dx.doi.org/10.1037/a0017415

Floyd, F. J., \& Widaman, K. F. (1995). Factor analysis in the development and refinement of clinical assessment instruments. Psychological Assessment, 7, 286-299. http://dx.doi.org/ 10.1037//1040-3590.7.3.286

Gomes, E. (2008). Validação da versão portuguesa de uma escala de competências sociais para crianças [Validation of the portuguese version of one social competence scale for children]. (Unpublished master's thesis), ISCTE - Lisbon University Institute, Lisbon, Portugal.

Granic, I., \& Patterson, G. R. (2006). Toward a comprehensive model of antisocial development: A dynamic systems approach. Psychological Review, 113, 101-131. http://dx.doi.org/10.1037/ 0033-295X.113.1.101

Greenberg, M., Domitrovich, C., \& Bumbarger, B. (2001). The prevention of mental disorders in school-aged children: Current state of the field. Prevention \& Treatment, 4, Article 1 a. http://dx.doi.org/10.1037//1522-3736.4.1.41a

Gresham, F. M., \& Elliott, S. N. (1984). Assessment and classification of children's social skills: A review of methods and issues. School Psychology Review, 13, 292-301. 
Gresham, F. M., \& Elliott, S. N. (1990). The social skills rating system. Circle Pines, MN: American Guidance Service.

Gresham, F., M., \& Elliott, S. N. (2008). Base rates of social skills acquisition/performance deficits, strengths, and problem behaviors: An analysis of the social skills improvement system - rating scales. Psychological Assessment. Advance online publication

Hu, L., \& Bentler, P. M. (1999). Cutoff criteria for fit indexes in covariance structure analysis: Conventional criteria versus new alternatives. Structural Equation Modeling, 6(1), 1-55. http://dx.doi.org/10.1080/10705519909540118

Kline, R. B. (1998). Principles and practices of structural equation modeling. New York, NY: The Guilford Press.

Lemos, M., \& Meneses, H. (2002). A avaliação da competência social: Versão portuguesa da forma para professores do SSRS [Social competence assessment: The portuguese version of SSRS teacher scale]. Psicologia: Teoria e Pesquisa, 18, 267-274. http://dx.doi.org/10.1590/S0102-37722002000300005

Major, S. O. (2007). Avaliação de aptidões sociais e problemas de comportamento em idade pré-escolar: Estudo exploratório com crianças portuguesas [Assessment of social skills and behavior problems in the pre-school: An exploratory study with portuguese children]. (Unpublished master's thesis). University of Coimbra, Coimbra, Portugal.

Major, S. O., \& Seabra-Santos, M. J. (2009). Assessment of social skills and problem behaviors in preschool age: Parent-teacher agreement for Portuguese children. In Book of Abstracts of the $10^{\text {th }}$ European Conference on Psychological Assessment (p. 145). Ghent, Belgium: Ghent University.

Maroco, J. (2010). Análise de equações estruturais: Fundamentos teóricos, software \& aplicações [Structural equation analysis: Theoretical fundaments, software and applications]. Lisbon, Portugal: Edições Sílabo.
Merrell, K. W. (1993a). School Social Behavior Scales. Eugene, OR: Assessment-Intervention Resources.

Merrell, K. W. (1993b). Using behavior rating scales to assess social skills and antisocial behavior in school settings: Development of the School Social Behavior Scales. School Psychology Review, 22, 115-133.

Merrell, K. W. (2001). Assessment of children's social skills: Recent developments, best practices, and new directions. Exceptionality, 9, 3-18. http://dx.doi.org/10.1207/S15327035 EX091\&2_2

Merrell, K. W. (2002). School Social Behavior Scales, Second Edition. Eugene, OR: Assessment-Intervention Resources.

Pedro, C., \& Albuquerque, C. P. (2007). Questionário de avaliação de aptidões sociais: SSRS - versão alunos [Social skills assessment questionnaire: SSRS - student version]. Psychologica, 45, 87-102.

Schmidt, M. E., DeMulder, E. K., \& Denham, S. A. (2002). Kindergarten social-emotional competence: Developmental predictors and psychosocial implications. Early Child Developmental and Care, 172, 451-462. http://dx.doi.org/ 10.1080/03004430214550

Segars, A. H., \& Grover, V. (1993). Re-examining perceived ease of use and usefulness: A confirmatory factor analysis. MIS Quarterly, 17, 517-525. http://dx.doi.org/10.2307/249590

Wentzel, K. R, \& Watkins, D. E. (2002). Peer relationships and collaborative learning as contexts for academic enablers. School Psychology Review, 31, 366-377.

Yukai-Yuksel, M. (2009). A Turkish version of the School Social Behavior Scales (SSBS). Educational Sciences: Theory \& Practice, 9, 1633-1650.

Received January 25, 2011

Revision received July 18, 2011 Accepted September 12, 2011 